\title{
An Overview of Compact Flourescent Lamp Retrofitting In Nigeria: Case Study of Hostel Environment in University Of Lagos
}

\author{
Igwilo.O.C. ${ }^{1 *}$, Abolarin.S.M. ${ }^{1}$,Eguma.C.A. ${ }^{1}$, Adegbenro.O. ${ }^{1}$ \\ ${ }^{I}$ National Center for Energy Efficiency and Conservation(Energy Commission of Nigeria), Faculty of \\ Engineering, University of Lagos, Lagos, Nigeria
}

\begin{abstract}
This case study cuts across the evaluation of the performance of the use of compact tubes in the University of Lagos hostel environment .Data were collected by means of questionnaires centralized basically on three major areas; the level of awareness of the students with compact fluorescent tube,the current Luminaire information data and finally, the beneficiary experiences and reactions to the retrofitting project of compact fluorescent lamps which has already been executed prior to the review on the evaluation. The latter of the three major areas of case study was solely based on perception of the students which could be affected by psychological,health and environmental factors.A chart of the evaluation of twenty questions in the questionnaire given to each student whose total population is over 500 in the environment of study was demonstrated. Project test duration is two hundred and fifty days. Also, an energy/cost audit calculation were carried out. We found out that about $3197 \mathrm{kw}-\mathrm{hr} / \$ 41,145.39$ can be saved by retrofitting the 36 watt fluorescent tube with CFL and about 45,662kw-hr/ \$587,669.90 for the 60 watt incandescent fluorescent tubes to compact tubes per 120-rooms hostel at a unit cost of $12.87 \mathrm{per} \mathrm{kw} / \mathrm{hr}$. For effective application, we also calculated house hold use.
\end{abstract}

Key words: Compact, CFL, Fluorescent, Lamp, Naira

\section{Introduction}

In recent times in some developing countries, some projects have been undertaken to phase out incandescent lamps which were replaced with compact fluorescent tubes. As at $10^{\text {th }}$ of August 2010 for example ,India had already planned to replace 400 million incandescent bulbs with compact fluorescent tubes saving $6000 \mathrm{MW}$ annually $(1,2)$ This indicates that developing countries are waking up to the fact that energy-saving compact fluorescent lamp is very vital in energy management in a country. It should be noted that replacement of incandescent tubes with compact fluorescent tubes in developing countries or economies will lead to reduction in energy consumption annually. This development will in turn reduce the capital waste in budgeting for more power projects that might not be needed or channeling the excess power that could be sold internationally to generate more revenue for the Country. In places like Nigeria, the macroscopic level of awareness $(3,4)$ in the use of energy-efficient bulbs, is seriously very low, indicating that more work disseminating information and creating awareness of compact fluorescent tubes have to be carried out more frequently.

Due to the fact that cfls are initially more expensive considering the initial switch-over investment (5), the government should put in more effort in funding initially energy-efficiency projects, considering the high return on the investment at the long term. Firstly, the government should also involve stake holders in reducing the prices of cfls (1).The government could come up with incentives and good marketing strategies that will coax the populace to buy into this project. However, the masses have a part to play also, in improvising of funds. The government duty here is to carry the implementation of the project and also help in subsidizing for funds if possible or needed. We are still buttressing the need for the government's approval and involvement based on the fact that, if this retrofitting exercise is carried out by individual business enterprises relevant to distribution of cfls for profit purposes, this might delay the significant impact being expected in the overall populace (3). Hence Government should be the initial driver for such global projects. There should be tax incentives for industries or institutions that invest in such energy saving projects.

The significant advantage of compact fluorescent tube cannot be over emphasized. This study gives a breakdown structure of the analysis found from the evaluation and review of compact fluorescent cfl retrofitting exercise in a school hostel after two hundred and fifty days. We will also indicate the amount of energy and the cost that can be saved from the retrofitting exercise. The application of this study model to the entire Nigeria environment will save Billions of Nigerian Naira energy equivalent. 


\section{Objective}

* To buttress the importance of energy saving initiative.

* To highlight the general performance of CFL over incandescent and fluorescent tubes.

* To create more awareness for the distribution,supply and implementation of CFL bulbs for house hold,office and industrial use,as this would reduce the energy demands thus reducing cost of energy.

\section{Methodology}

First of all, a retrofitting exercise was undertaken in the hostel environment, which involved replacing the previously conventionally used 36watt fluorescent tube with about 14 watt compact fluorescent tubes.

After two hundred and fifty days (250) usage of the new compact fluorescent tube, questionnaires were distributed to capture the necessary data.

We made use of excel to gather all data from questionnaire. We created tables and designed charts that will use the results obtained to give clear feedback evaluation picture of the impact of the CFL switch-over project.

\subsection{Assumptions}

* It was assumed that each room was retrofitted with two CFL bulbs owing to the fact that most of the rooms only had two fittings except the common room, the reading room and the shop outlets which had extra fittings making it a total of three fittings for each of the rooms mentioned.

* It should also be assumed that one hundred and eleven student answered the questionnaire which was in shortened number of the 120 rooms which were retrofitted.This indicates that a percentage error will be calculated.

Questionnaires were distributed to capture the necessary data from 111 student occupants in this hostel of study. It should be noted that about 120 rooms were covered in this hostel.

It should be noted that the questionnaires were answered according to perception of the student representative. It should be noted that over $240 \mathrm{CFL}$ bulbs were used in the retrofitting exercise to replace the 36 watt fluorescent tubes in each room.

The questionnaire was comprised of compact fluorescent feedback form to access the performance, durability and sustainability of the compact fluorescent tube to ascertain whether this new technology has withstood the test of time or whether the quality control should be reviewed.

The questionnaire focused on three area (see attached the sample of the questionnaire)

* Understanding consumer knowledge and perception of energy efficiency/CFLS,

* the current luminaire information data and finally;

* The beneficiary experiences and reactions to the project.

\subsection{Energy Audit Data Collection}

To obtain the energy consumption data, we collected data from question 7 and 13 of the questionnaire, which cover how long the student left the lamp on and the wattage of the lamp respectively. However, for optimum data collection we picked the highest limit of hours spent leaving the lamp on each day, and from investigation we noted that during that switch-over project 14watt bulbs were suppose to have been installed but some had 11 watt capacity label. We did take care of the effects of this anomaly by multiplying each cfl power capacity by the total consumed hours each day using excel calculator programme to obtain the total watt hours,we then divided by 1000 to get the $\mathrm{kw} / \mathrm{hr}$. We then multiplied by 2 to cover up for the two lamps per room. We then multiplied for the total of the 250 days.

This was executed by the use of excel programming, which suited this purpose.

\subsubsection{Comparison Data For Energy Audit Simulation for 36 Watt Fluorescent Tube}

We simulated the energy data collection for the previously used 36 watt bulbs $(6,7,8)$; we used data collated to multiply the duration in which the lamp is left on by 36 watt fluorescent tube to know the amount that was left on for 250 days.

\subsubsection{Comparison Data for Energy Audit Simulation for 60 Watt Incandescent Bulb}

We also simulated for the 60 watt incandescent bulb which is used in house hold compartments, we got the total energy used by multiplying 60 watt by each of the time duration of the bulbs simulated to be left on if also utilized in each room. We then calculated difference by subtracting the total energy utilized by the CFL LAMP from the total energy utilized by the 60 watt incandescent lamp. 


\subsubsection{Determination of the Percentage Error Encountered during the Retrofitting Process.}

It should also be noted that over 120 rooms were retrofitted, but the questionnaire indicated just 111 rooms excluding the three bulbs for the common room and shop. Therefore, we calculated the percentage error resulting from these differences to be $\pm 7.4 \%$.

\subsection{Energy Audit Result}

\section{Results/Discussion}

We got the total energy utilized by the compact fluorescent tube(2 lamps per room) for two hundred and fifty days .The energy utilized amounted to $14,038 \mathrm{KW}-\mathrm{Hr}$.We also simulated the result for the total energy used for the 36 watt bulb. It amounted to $18135 \mathrm{KW}-\mathrm{HR}$. We also simulated for house hold incandescent bulb which amounted to $60,600 \mathrm{KWHR}$.

The results generated from the project using the Excel Sheet application showed that $3197 \mathrm{kw}-\mathrm{hr}$ and $45662 \mathrm{kw}-\mathrm{hr}$ of power can be saved by retrofitting with 36 watt and 60 watt bulbs respectively with compact fluorescent tube.

\subsection{Cost Audit Result}

The first and most important finding is the cost that could be saved by CFL retrofitting exercise. We found out that about $\$ 41,145.39$ can be saved by retrofitting the 36 watt fluorescent tube with CFL and about $\$ 587,669.90$ for the 60 watt incandescent house hold simulation can be saved keeping unit cost at $\$ 12.87$ per kw-hr. It should also be noted that over 120 rooms were retrofitted, but the questionnaire indicated just 111 rooms excluding the three bulbs for the common room and shop. This exercise was executed for over 250 days. We can deduce that the application of this cost audit as a result of the energy conserved by the retrofitting exercise, will significantly save more cost and energy that could be utilized to support more businesses for employment generation.

We found out that over $81 \%$ of the students were aware of energy efficiency and conservation. About $19 \%$ were not aware.It indicates the fact that more awareness needs to be created generally in order to inform the populace of energy efficiency, but as we can see, only $19 \%$ of the students were novice.

From my investigation we noted that over $100 \%$ used 14 watts bulb. We also found out from that about $95 \%$ of the students are aware of switching off the lamps in the day and making use of natural day light.We matched this result using a pie chart to indicate the percentage of each property of each feedback form. We got the result that over $3 \%$ left their lights on from $1-5 \mathrm{hrs}, 9 \%$ left their lights on from $6-10 \mathrm{hrs}, 28 \%$ left their lights on from $11-15 \mathrm{hrs}$, about $35 \%$ left their lights on from $16-20 \mathrm{hrs}$ and finally about $25 \%$ left their lights on from $21-24 \mathrm{hrs}$.From the result it shows that just over $12 \%$ use natural light and save energy,and about over $55 \%$ of the student to practice what they believe in.So emphasis needs to be placed on practicing what we preach as this is reflected that over $95 \%$ believe in saving light energy during the day,but about over $55 \%$ don't practice that.

Fig 1 pie chart indicates that over $55 \%$ do not utilize the natural light energy. This is very disappointing and will not prolong the life span of the CFL lamp. Fig 2 indicates that $95 \%$ are aware of the daylight saving energy initiative but do not practice it. We will also represent the percentage of the student that rated the brightness of the CFL LAMP which is very important for readability. This is demonstrated in the pie- chart. We can see a wide number precisely about $87 \%$ rated it as good. This indicates the general acceptance of CFL for readability standards and this rating could be marked at $95 \%$.

For heat emission we would give the result of the finding of the percentage of student who said YES OR NO that CFL cause heat or not. Fig 4 indicates the general light output is relatively good (over $96 \%$ ). We can see infer that CFL LAMPS hardly released heat. This means they have little heat emissions making it conducive for people in tropical regions of the world. It should be noted in design of lighting technology that readability should be put into consideration. From our survey we noted that $84 \%$ rated this CFL LAMPS as having good readability standards, the rest of the $16 \%$ could have just been skeptical or it was probably due to environmental and internal perception factors.

Fig 6 rates the life span of the CFL after duration of 250 days. It was noted that the overall rating was $96 \%$ very good life span. This is very encouraging. In design and marketing, we have to take in the remark of the consumer or customer, because the customer is always right. We discovered that over $99 \%$ rated the appearance or the physical design of the build as very good. This result indicates it has an excellent appearance. 
FIGURES \& TABLES

\section{Q7 duration of hours used by bulb}

$\square 1-5 \mathrm{hrs}=6$-10hrs $\square 11-15 \mathrm{hrs} \square 16-20 \mathrm{hrs}=21-24 \mathrm{hrs}$

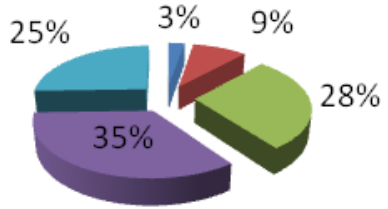

fig 1: q7 duration of hours used by bulb

\section{Q4percentage aware of daylight energy} saving

$$
5 \% \square \text { YES } \square \text { NO }
$$

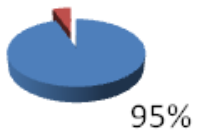

fig 2: q4 percentage aware of daylight energy saving

\section{Q17 HEAT EMMISION PERCEPTION RATING}

$$
\text { 보 }=\text { NO }
$$

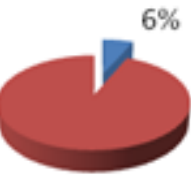

$94 \%$

fig 3: q17 heat emission perception rating 


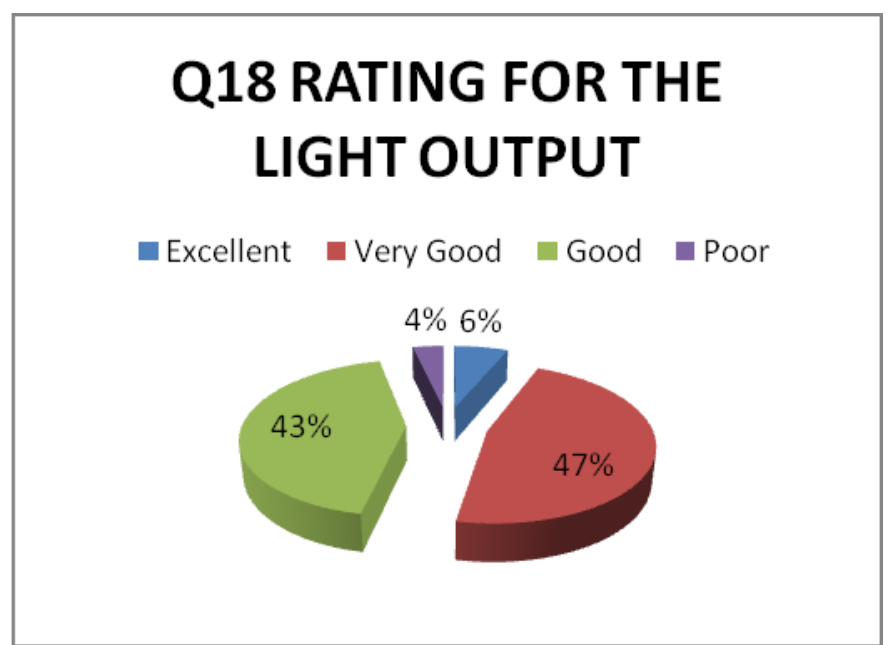

fig 4: q18 rating for the light output

\section{Q19 readability rating}

$\square Y E S \backsim N O$

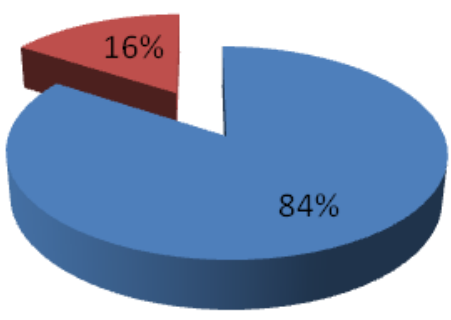

fig 5: q19 readability rating

\section{Q20 life span rating}

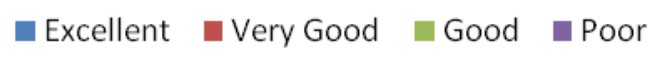

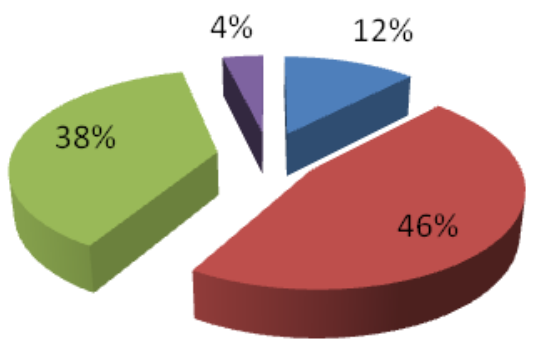

fig 6: q20 life span rating 


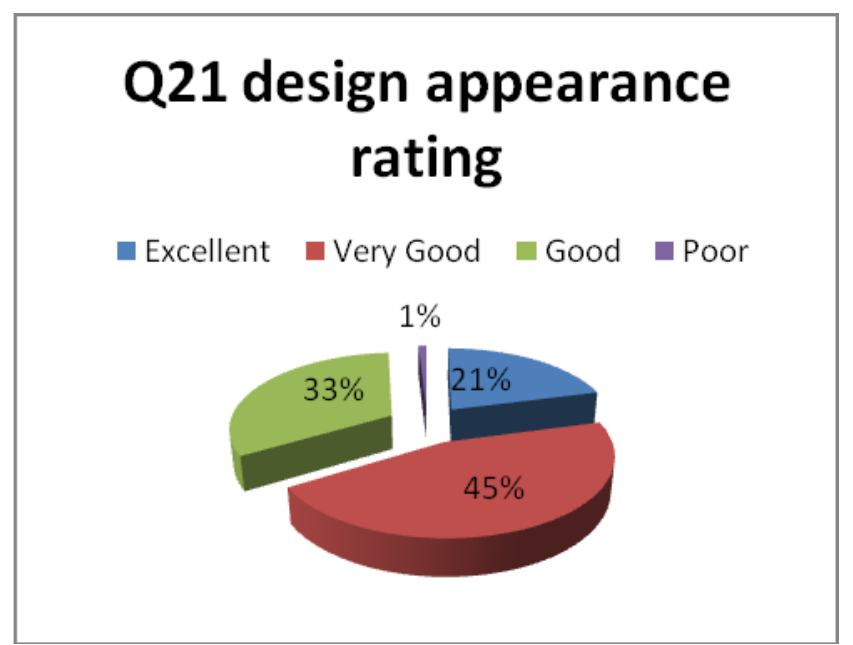

fig 7: q21 design appearance rating

\subsection{Limitation and Future Studies}

\section{Conclusion}

* The intermittent switching on and off of the CFLS could make it less sustainable. However, they are supposed to last for 10000 hours. They should be left on for a while without being turned on and off frequently for optimum performance.

* Not all CFLS can be used with dimmers or regulators. A regular CFL if used with dimmer will burn off quickly. One has to check package before use.

* CFL Lamps used outdoors must be protected from weather elements.

* They have high sensitivity to temperatures and can cause lower light levels. The lower the temperature, the lower the light level. This indicates it is not readily suitable for high temperate or low temperature regions.

* CFLS are not suitable for towered or spot lights, or where narrowed beams of light are required. They are only designed for ambient lighting.

- If a CFL is broken or burnt, the mercury is being released, and the presence of mercury makes it hazardous to the environment. It should be noted that if not correctly disposed, it could intoxicate the environment, because mercury is naturally a toxic metal in study of chemistry.

More work should be done to create designs for CFL that will be used in spot lights which will help the entertainment industry and could also be used for auditorium or conference hall services.

From the result of the energy audit in comparison with the energy that would have been expended by a 36 watt bulb and 60 watt incandescent bulb with the CFL bulbs based on simulation,it can be inferred that CFL could save a significant amount of energy therefore reducing the initial cost.It can also drastically reduce the overall cost spent on energy consumption.It could also be noted that the light output is relatively the same in comparison with the 36 watt bulb and 60 watt in candescent bulb, which gives the same output for lesser amount of energy and cost.It should be noted that the conventional 60 watt incandescent bulb should be phased out and replaced by CFL as they have stood the test of time. More work should be done in increasing the awareness of the energy efficiency initiative at a macroscopic level of the populace in Nigeria and globally considering the economic impact of the current energy demand and limited supply.

\section{References}

[1]. The Bureau Energy Efficiency (BEE);Documentation of best practice.Lighting Energy Efficiency project under Bachat Lamp Y ajonascheme; 2001;3-5

[2]. BolajiF.SuleKajogbola R AlaoHabeeb A AJIMOTOKAN Mohammed K Garba; Compact fluorescent lamps and electricity consumption trend in residential buildings in Ilorin, Nigeria", International Journal of Energy Sector Management;5(2);2011;162168

[3]. United Nations Development Programme. Promoting Energy Efficiency in Residential and Public Sector in Nigeria; http://www.ng.undp.org/energy/EE-project-document.pdf.;2011;41-46

[4]. Lebot,B.;Energy Efficiency and Market Transformation:A short overview of Best Practices.A paper presented during the inception Workshop of the UNDP-GEF Project to promote Energy Efficiency in Residential and public building in Nigeria;2008.

[5]. MridulChadha earth industry http://earthandindustry.com/2010/05/india-to-launch-worlds-largest-cdm-project-will-replace-400million-incandescent-lamps-with-cfls; 2010;1-2

[6]. Thumann A and Younger WJ.Handbook of Energy Audit.Published by the Fairmont Press,Inc.2008

[7]. http://www.energymanagertraining.com/CDM/cdm main.htm

[8]. Furniture.about.com/od/accesoriesguide/0/cfladvant.htm by Ale Abbas 